\title{
Perineural Injection for Treatment of Root-Signature Signs Associated with Lateralized Disk Material in Five Dogs (2009-2013)
}

\author{
Sarah Giambuzzi ${ }^{1 *}$, Theresa Pancotto ${ }^{2}$ and Jeffrey Ruth ${ }^{2}$ \\ ${ }^{1}$ Lake Forest Animal Hospital, Forest, VA, USA, ${ }^{2}$ Department of Small Animal Clinical Sciences, Virginia Maryland College of \\ Veterinary Medicine, Blacksburg, VA, USA
}

OPEN ACCESS

Edited by: Sarah A. Moore, The Ohio State University, USA

Reviewed by: Bianca Hettlich, Vetsuisse Bern, Switzerland Sheila Carrera-Justiz, University of Florida, USA

*Correspondence: Sarah Giambuzz seg219@vt.edu

Specialty section: This article was submitted to Veterinary Neurology and Neurosurgery,

a section of the journa Frontiers in Veterinary Science

Received: 25 October 2015 Accepted: 04 January 2016 Published: 27 January 2016

Citation:

Giambuzzi S, Pancotto T and Ruth J (2016) Perineural Injection for Treatment of Root-Signature Signs Associated with Lateralized Disk Material in Five Dogs (2009-2013).

Front. Vet. Sci. 3:1. doi: 10.3389/fvets.2016.00001
Intervertebral disk disease (IVDD) is common in dogs; cervical IVDD accounts for $13-25 \%$ of all cases. Ventral slot decompression provides access to ventral and centrally extruded or protruded disk material. However, procedures to remove dorsally or laterally displaced material are more difficult. This case series describes the use of perineural injection as a potential treatment option for dogs experiencing root-signature signs associated with lateralized disk material in the cervical spine. Five dogs underwent fluoroscopically guided perineural injection of methylprednisolone \pm bupivacaine. Most patients experienced improvement in root-signature signs and remained pain free without the assistance of oral pain medication. These findings suggest the perineural injection of methylprednisolone \pm bupivacaine represents a viable option for dogs with cervical lateralized disk material causing root-signature signs.

Keywords: perineural, root-signature, intervertebral disk disease, lateralized disk, fluoroscopy

\section{INTRODUCTION}

Intervertebral disk disease (IVDD) is common in dogs, especially in chondrodystrophic breeds (1). Cervical IVDD accounts for 13-25\% of all cases (1). Medical management consists of cage rest, antiinflammatory medications, muscle relaxants, and/or opioid agents. Surgical intervention is often required, due to poor response to medical therapy (2). Surgical options in the cervical region include ventral fenestration, ventral slot decompression, dorsal laminectomy, and hemilaminectomy (3-7). The ventral slot approach is the preferred method for ventrally located extrusions or protrusions (8). However, this approach may not provide access to lateralized or foraminal disk material. In such cases, dorsal laminectomy or hemilaminectomy has been used, though these procedures are more difficult, time consuming, expensive, and painful (3-7). Complications are more common with dorsal and lateral techniques compared to ventral slot and include hemorrhage, post-operative neurological deterioration, and prolonged recumbancy $(7,9,10)$.

This case series describes the use of fluoroscopically guided perineural injection for dogs experiencing root-signature signs associated with lateralized disk material in the cervical spine.

\section{BACKGROUND}

Client-owned animals at the VMCVM veterinary teaching hospital that had undergone cervical, fluoroscopically guided perineural injection were retrospectively identified. For inclusion, all dogs 
had to have computed tomography (CT) (Toshiba Aquilon 16, Toshiba American Medical Systems Inc., Tustin, CA, USA) or magnetic resonance (Intera 1.5-T, Philips Healthcare, Eindhoven, Netherlands) findings of cervical, lateralized intervertebral disk material, and a complete medical record. Case histories are summarized in Table $\mathbf{1}$.

For the perineural injection, each dog was positioned in lateral recumbency, affected side up, on the table of a digital fluoroscopy system (Shimadzu YSF-120 Digital R/F System, Shimadzu Medical Systems, Torrance, CA, USA). A $5 \mathrm{~cm} \times 5 \mathrm{~cm}$ area over the appropriate disk space on the lateral cervical spine was clipped and scrubbed. Fluoroscopy was used to guide needle placement (Figure 1). A 20 gage $1.5^{\prime \prime}$ spinal needle was inserted from a dorsolateral direction until it contacted the articular process or lamina and then repositioned ventrally or caudally until superimposed with the target intervertebral foramen. Average procedural time was $25 \mathrm{~min}$.

On admission to the VMCVM teaching hospital, clients provide written consent for teaching and investigational purposes via a standard treatment authorization form. All clients provided verbal consent for the treatment when therapeutic options were discussed. Each of these patients received follow-up phone calls as well and at the end of the phone conversation they were told that a case report was in the process and verbal consent was received.

\section{Case 1}

A 10-year-old, neutered male Dachshund was presented for evaluation of severe neck pain that began 1 month earlier. Treatment

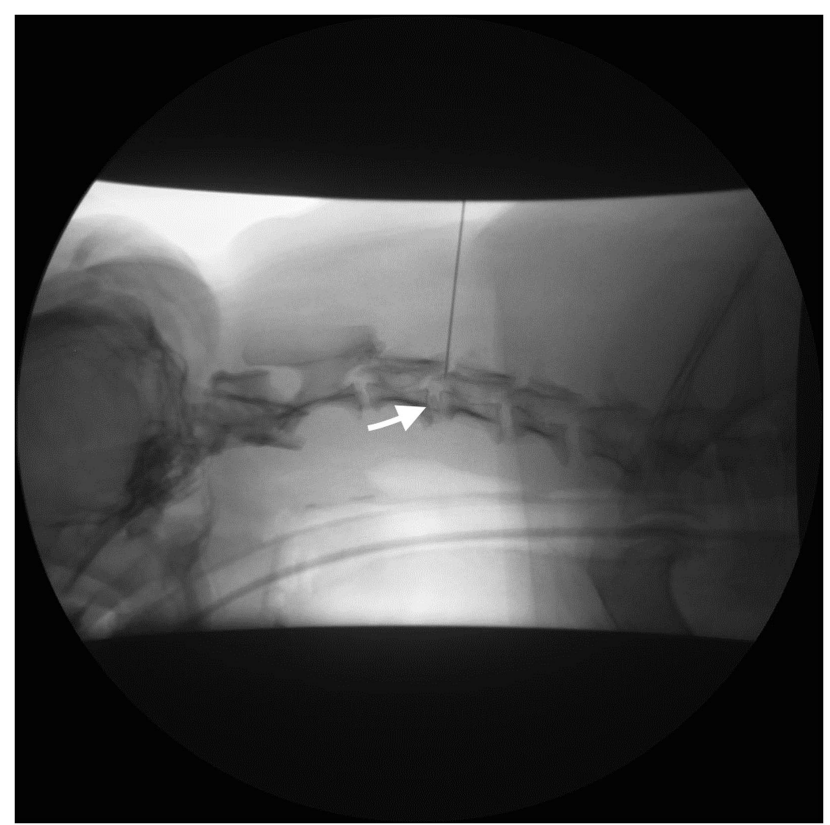

FIGURE 1 | Left lateral fluoroscopic projection of the cervical vertebral column (Case 1). A spinal needle is inserted dorsally at the level of the C3-C4 intervertebral foramen. Opacification of the C3-C4 intervertebral disk and foramen is also apparent (arrow). prior to referral included deracoxib, tramadol, and cage rest. On presentation, physical and neurological examinations identified cervical pain and lameness of the left forelimb. Orthopedic examination was normal.

Computed tomography of the cervical spine was performed. At C3-C4, the intervertebral disk space was collapsed and a large amount of mineral-attenuating material was present in the left intervertebral foramen, displacing the perineural fat (Figure 2). Incidentally, in situ mineralization of the intervertebral disks was noted throughout the remainder of the cervical vertebral column.

The lateralized material at $\mathrm{C} 3-\mathrm{C} 4$ was thought to contribute to clinical signs due to compression of the left third spinal nerve, and its location suggested that it would not be accessible through a ventral slot approach. Interventional options included cervical hemilaminectomy or fluoroscopically guided perineural injection of local anesthetic (bupivacaine) and methylprednisolone. The client elected the latter.

Twenty milligrams of methylprednisolone $(2.1 \mathrm{mg} / \mathrm{kg})$ and $9.4 \mathrm{mg}$ of bupivacaine $(1 \mathrm{mg} / \mathrm{kg}$ ) were injected into the left C3-C4 foramen. The patient was moved to the ICU after the procedure for recovery. Although the patient became increasingly alert, he initially failed to regain voluntary respiration. Mechanical ventilatory support was required for $30 \mathrm{~min}$; later, the patient began breathing on his own, was weaned off the ventilator, and was extubated.

Immediate improvement in lameness was apparent while in the hospital. The patient was discharged with tramadol PO $(1.4 \mathrm{mg} /$ $\mathrm{kg} \mathrm{q} 8 \mathrm{~h}$ ) and gabapentin PO (5.5 mg/kg q12 h) to be combined

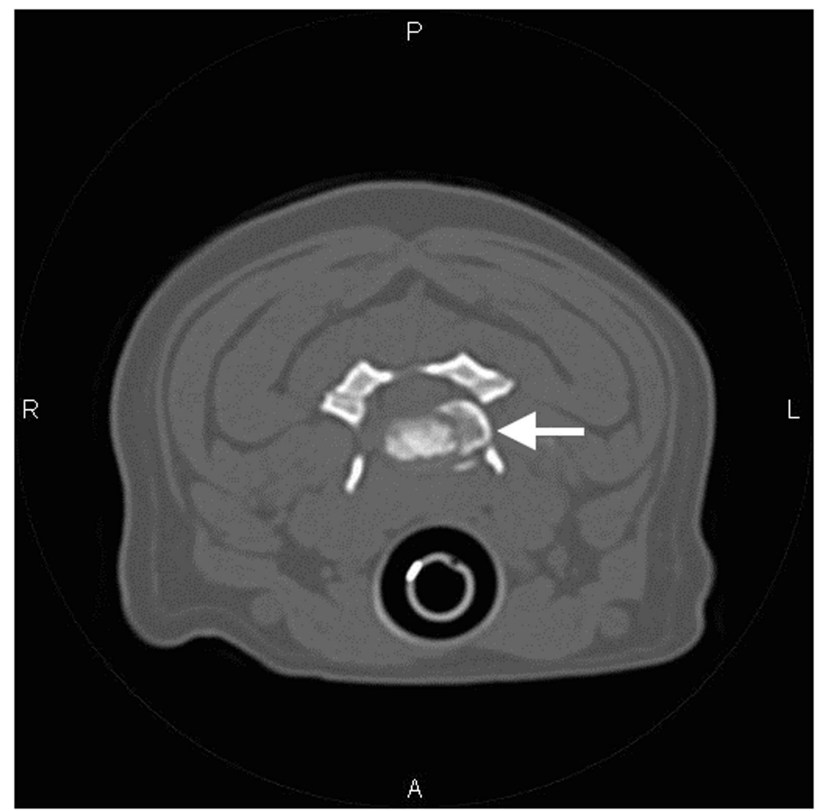

FIGURE 2 | Transverse CT image of the cervical spine at the level of C3-C4 (Case 1). Mineral-attenuating material is apparent in the left intervertebral foramen (arrow). There is also mineralization of the nucleus pulposus that remains in situ. 
TABLE 1 | Summary of patient data.

\begin{tabular}{|c|c|c|c|c|c|c|c|c|c|}
\hline $\begin{array}{l}\text { Case/ } \\
\text { signalment }\end{array}$ & Clinical signs & $\begin{array}{l}\text { Rx at } \\
\text { presentation }\end{array}$ & $\begin{array}{l}\text { Imaging } \\
\text { type }\end{array}$ & Pertinent imaging findings & Injected Rx & Oral $\mathbf{R x}$ & Complications & Outcome & Follow-up \\
\hline $\begin{array}{l}10 \text { years } \mathrm{CM} \\
\text { Dachshund }\end{array}$ & $\begin{array}{l}1 \text { month cervical } \\
\text { pain, left forelimb } \\
\text { root-signature } \\
\text { signs }\end{array}$ & $\begin{array}{l}\text { Deraxocib, } \\
\text { tramadol }\end{array}$ & $\mathrm{CT}$ & $\begin{array}{l}\text { Left lateralized extrusion of } \\
\text { mineralized disk material at } \\
\text { C3-C4, causing presumed } \\
\text { compression of the left third } \\
\text { spinal nerve root }\end{array}$ & $\begin{array}{l}\mathrm{C} 3-\mathrm{C} 4 \\
2.1 \mathrm{mg} / \mathrm{kg} \\
\text { methylprednisolone } \\
1 \mathrm{mg} / \mathrm{kg} \\
\text { bupivacaine }\end{array}$ & $\begin{array}{l}1.4 \mathrm{mg} / \mathrm{kg} \text { tramadol } \\
\text { q8 } \mathrm{h} \\
5.5 \mathrm{mg} / \mathrm{kg} \text { gabapentin } \\
\mathrm{q} 12 \mathrm{~h}\end{array}$ & $\begin{array}{l}\text { Transient } \\
\text { respiratory } \\
\text { paralysis }\end{array}$ & $\begin{array}{l}\text { Immediate } \\
\text { resolution } \\
\text { of pain and } \\
\text { root-signature } \\
\text { sings }\end{array}$ & $\begin{array}{l}2 \text { weeks - pain free } \\
4 \text { years - pain free, medication } \\
\text { free, no recurrence }\end{array}$ \\
\hline $\begin{array}{l}10 \text { years } M \\
\text { Lhasa apso }\end{array}$ & $\begin{array}{l}1 \text { week cervical } \\
\text { pain, left forelimb } \\
\text { root-signature } \\
\text { signs }\end{array}$ & $\begin{array}{l}\text { Meloxicam, } \\
\text { diazepam }\end{array}$ & $\begin{array}{l}\text { CT and } \\
\text { MRI }\end{array}$ & $\begin{array}{l}\text { Left lateralized extrusion of } \\
\text { mineralized disk material at C3- } \\
\text { C4 causing compression of the } \\
\text { left third spinal nerve root }\end{array}$ & $\begin{array}{l}\mathrm{C} 3-\mathrm{C} 4 \\
2.1 \mathrm{mg} / \mathrm{kg} \\
\text { methylprednisolone }\end{array}$ & $\begin{array}{l}3.2 \mathrm{mg} / \mathrm{kg} \text { tramadol } \\
\mathrm{q} 8-12 \mathrm{~h} \\
6.4 \mathrm{mg} / \mathrm{kg} \text { gabapentin } \\
\mathrm{q} 12 \mathrm{~h}\end{array}$ & None & $\begin{array}{l}\text { Immediate } \\
\text { improvement }\end{array}$ & $\begin{array}{l}1 \text { month - pain free } \\
3 \text { years - pain free, medication } \\
\text { free, no recurrence }\end{array}$ \\
\hline $\begin{array}{l}13 \text { years SF } \\
\text { mixed breed } \\
\text { dog }\end{array}$ & $\begin{array}{l}2 \text { weeks cervical } \\
\text { pain, left forelimb } \\
\text { root-signature } \\
\text { signs }\end{array}$ & $\begin{array}{l}\text { Methocarbamol, } \\
\text { gabapentin, } \\
\text { tramadol }\end{array}$ & MRI & $\begin{array}{l}\text { Left lateralized extrusion of } \\
\text { disk material at C5-C6 causing } \\
\text { compression of the left fifth } \\
\text { spinal nerve root }\end{array}$ & $\begin{array}{l}\text { C5-C6 } \\
1 \mathrm{mg} / \mathrm{kg} \\
\text { methylprednisolone }\end{array}$ & $\begin{array}{l}5 \mathrm{mg} / \mathrm{kg} \text { tramadol } \\
\mathrm{q} 12 \mathrm{~h} \\
10 \mathrm{mg} / \mathrm{kg} \text { gabapentin } \\
\mathrm{q} 8-12 \mathrm{~h} \\
25 \mathrm{mg} / \mathrm{kg} \\
\text { methocarbamol } \mathrm{q} 24 \mathrm{~h}\end{array}$ & None & $\begin{array}{l}\text { Marked } \\
\text { improvement } \\
\text { within } 1 \text { week }\end{array}$ & $\begin{array}{l}6 \text { months - continued } \\
\text { improvement, gabapentin PRN }\end{array}$ \\
\hline $\begin{array}{l}11 \text { years } \mathrm{CM} \\
\text { mixed breed } \\
\text { dog }\end{array}$ & $\begin{array}{l}1 \text { week cervical } \\
\text { pain, tetraparesis, } \\
\text { left forelimb root- } \\
\text { signature signs }\end{array}$ & None & MRI & $\begin{array}{l}\text { Left lateralized protrusion of } \\
\text { disk annulus at C6-C7 causing } \\
\text { compression of the left sixth } \\
\text { spinal nerve root }\end{array}$ & $\begin{array}{l}\mathrm{C} 6-\mathrm{C} 7 \\
1 \mathrm{mg} / \mathrm{kg} \\
\text { methylprednisolone }\end{array}$ & $\begin{array}{l}3-4.4 \mathrm{mg} / \mathrm{kg} \text { tramadol } \\
\text { q8 } \mathrm{h} \\
5.9-11.8 \mathrm{mg} / \mathrm{kg} \\
\text { gabapentin } \mathrm{q} 12 \mathrm{~h} \\
\text { Prednisone } 1.2 \mathrm{mg} / \\
\mathrm{kg} \mathrm{q} 12 \mathrm{~h}\end{array}$ & None & $\begin{array}{l}\text { Improved pain } \\
\text { control within } \\
2 \text { weeks }\end{array}$ & $\begin{array}{l}3 \text { months - pain free, } \\
\text { medications discontinued } \\
1 \text { year - pain free, medication } \\
\text { free, no recurrence }\end{array}$ \\
\hline $\begin{array}{l}6 \text { years } \mathrm{CM} \\
\text { Dachshund }\end{array}$ & $\begin{array}{l}2 \text { weeks } \\
\text { cervical pain } \\
\text { and left forelimb } \\
\text { root-signature }\end{array}$ & $\begin{array}{l}\text { Tramadol, } \\
\text { methocarbamol, } \\
\text { prednisone }\end{array}$ & MRI & $\begin{array}{l}\text { Left lateralized extrusion of disk } \\
\text { material at } \mathrm{C} 6-\mathrm{C} 7 \text { causing mild } \\
\text { spinal cord compression and } \\
\text { compression of the left sixth } \\
\text { spinal nerve root }\end{array}$ & $\begin{array}{l}\mathrm{C} 6-\mathrm{C} 7 \\
1 \mathrm{mg} / \mathrm{kg} \\
\text { methylprednisolone }\end{array}$ & $\begin{array}{l}2.5 \mathrm{mg} / \mathrm{kg} \text { tramadol } \\
\mathrm{q} 8-12 \mathrm{~h} \\
10 \mathrm{mg} / \mathrm{kg} \text { gabapentin } \\
\mathrm{q} 8-12 \mathrm{~h} \\
1 \mathrm{mg} / \mathrm{kg} \text { prednisone } \\
\text { q12 } \mathrm{h}\end{array}$ & None & $\begin{array}{l}\text { Mild } \\
\text { improvement in } \\
\text { hospital }\end{array}$ & $\begin{array}{l}3 \text { weeks - moderate } \\
\text { improvement } \\
2-3 \text { months - continued } \\
\text { improvement and } \\
\text { discontinuation of prednisone } \\
\text { and tramadol; gabapentin PRN }\end{array}$ \\
\hline
\end{tabular}


with cage rest and physical therapy. Fourteen days later at followup, the patient was doing well and was pain free. Tramadol was discontinued at that time, and the dose of gabapentin was reduced by half. By 3 months after surgery, all medications had been discontinued. Follow-up was obtained 4 years later when the patient was presented to the teaching hospital ophthalmology service for cataract evaluation. No recurrence of neck pain was reported by the client, and none was found on neurological examination.

\section{Case 2}

A 10-year-old, intact male Lhasa apso was presented for evaluation of acute severe neck pain and left forelimb lameness that was unsuccessfully treated with medical management, including meloxicam and diazepam, for 7 days prior to presentation. On presentation, physical and neurological examinations identified left forelimb lameness, cervical pain, and mild lumbosacral pain. Orthopedic evaluation was normal.

Computed tomography of the cervical spine was performed, using the aforementioned protocol. The findings included intervertebral disk space narrowing at $\mathrm{C} 3-\mathrm{C} 4$ with an aggregation of mineral-attenuating material in the left intervertebral foramen and in situ mineralization of the intervertebral disk. Incidentally, there was also in situ mineralization of the intervertebral disk at C7-T1. Since no overt compressive spinal cord lesion was noted, cervical MR was performed to avoid administration of intrathecal contrast and provide a complete study. This revealed lateral disk extrusion into the left intervertebral foramen at C3-C4. The left third spinal nerve was not distinctly visualized in the foramen. There was also mild flattening of the ventral aspect of the cervical spinal cord at C2-C3 and C3-C4 secondary to hypertrophy of the dorsal longitudinal ligament and/or dorsal protrusion of the annulus fibrosis.

Treatment options were discussed and the client elected to have fluoroscopically guided perineural injection of $16 \mathrm{mg}$ methylprednisolone $(2.1 \mathrm{mg} / \mathrm{kg})$ of the $\mathrm{C} 3$ left nerve root. Oral medications (gabapentin $6.4 \mathrm{mg} / \mathrm{kg} \mathrm{q} 12 \mathrm{~h}$ and tramadol $3.2 \mathrm{mg} /$ $\mathrm{kg} \mathrm{q8-12} \mathrm{h)} \mathrm{were} \mathrm{continued.}$

Immediate improvement was apparent while in the hospital. The patient was discharged on the next day. The owner reported no pain at home following the procedure. All medications were discontinued 1 month after the procedure. Three years later, the patient had no recurrence of clinical signs reported by the owner via telephone follow-up.

\section{Case 3}

A 13-year-old, spayed female mix breed dog was presented for evaluation of cervical and left forelimb pain beginning 2 weeks prior. She was receiving methocarbamol, gabapentin, and tramadol. On presentation, the patient was stiff in the forelimbs with lameness in the forelimb. Guarding was noted on cervical manipulation, and orthopedic evaluation was normal. Radiographs taken previously by the referring veterinarian revealed collapse of the intervertebral disk spaces at C4-C5 and C5-C6.

Magnetic resonance imaging showed a small amount of contrast enhancing material within the extradural space on the left ventral aspect of the vertebral canal at C5-C6. This material minimally displaced the left portion of the spinal cord dorsally and caused compression of the left fifth spinal nerve root within the $\mathrm{C} 5-\mathrm{C} 6$ intervertebral foramen. The intervertebral disk nuclei at C2-C3, C3-C4, C4-C5, C5-C6, and $\mathrm{C} 6-\mathrm{C} 7$ were hypointense on all sequences, consistent with in situ degeneration. Narrowing of the ventral subarachnoid space was present at $\mathrm{C} 2-\mathrm{C} 3, \mathrm{C} 3-\mathrm{C} 4, \mathrm{C} 4-\mathrm{C} 5$, and C6-C7, suggesting mild non-compressive intervertebral disk protrusions.

Treatment options were discussed and the owner elected to proceed with cervical perineural injection of the left $\mathrm{C} 5$ nerve root. Methylprednisolone $(1 \mathrm{mg} / \mathrm{kg}$ ) was injected into the perineural space. The patient was sent home on methocarbamol $(25 \mathrm{mg} / \mathrm{kg})$ q24 h, gabapentin $(10 \mathrm{mg} / \mathrm{kg}) \mathrm{q} 8-12 \mathrm{~h}$, and tramadol $(5 \mathrm{mg} / \mathrm{kg})$ $\mathrm{q} 12 \mathrm{~h}$ as previously prescribed by the referring veterinarian for continued pain management.

Mild improvement in the patient's clinical status was observed during hospitalization, most notable a decrease in cervical pain. The patient returned for follow-up 1 week later and the owner reported marked improvement in cervical and forelimb pain; findings were confirmed on physical exam. Six-month telephone follow-up revealed continued improvement in both cervical and forelimb pain. Gabapentin had been continued as needed for pain after prolonged activity, but all other medication had been discontinued.

\section{Case 4}

An 11-year-old, neutered male mixed breed dog was presented for evaluation of an acute onset of severe neck pain and left forelimb lameness that worsened the week prior to presentation. He had received no treatment prior to presentation. Physical and neurological examinations identified mild tetraparesis and ataxia with left thoracic root-signature signs. Left forelimb lameness was noted with mild proprioceptive deficits in the left thoracic and pelvic limbs. The right forelimb was normal. Pain was apparent on cervical but not thoracolumbar manipulation. Orthopedic examination was normal. Findings were consistent with a lesion affecting the C6-T2 spinal nerves or spinal cord segments and T3-L3 spinal cord segments.

Magnetic resonance imaging of the cervical spine revealed that the nucleus of the intervertebral disk at C6-C7 was hypointense on all sequences, and there was mild broad-based dorsolateral protrusion of the $\mathrm{C} 6-\mathrm{C} 7$ intervertebral disk toward the left intervertebral foramen, compressing the left sixth nerve root. No spinal cord compression was noted.

Treatment options were discussed with the client. The client elected fluoroscopically guided perineural injection of methylprednisolone $(1 \mathrm{mg} / \mathrm{kg})$ into the area of the intervertebral foramen of C6-C7. Anesthetic recovery was uneventful.

Increased willingness to ambulate and improved voluntary range of motion of the head and neck were noted on exam the following morning; lameness was still present. The patient was subsequently discharged with gabapentin $(5.9-11.8 \mathrm{mg} / \mathrm{kg}$ PO BID), prednisone on a tapering dose beginning at $1.2 \mathrm{mg} /$ $\mathrm{kg} \mathrm{q} 12 \mathrm{~h}$ and tramadol (3-4.4 mg/kg PO q8 h). At the 2-week follow-up evaluation, the patient showed only mild pain during range of motion. Forelimb weakness and lameness were no 
longer evident. Prioprioception was improved in the left forelimb. T3-L3 signs were unchanged. Prednisone and tramadol were discontinued at this visit. Further telephone follow-up with the owner revealed that gabapentin was continued as needed for pain for 2-3 months then discontinued. The patient remained free from clinical signs of radicular pain but had succumbed to lymphoma 18 months later.

\section{Case 5}

A 6-year-old, neutered male Dachshund was presented for severe cervical pain. Medical management, including tramadol, methocarbamol, and prednisone, was attempted for 2 weeks prior to presentation. Physical and neurological examinations identified lameness in the left forelimb and cervical pain. Mild postural reaction deficits and decreased spinal reflexes were noted in the left forelimb. Orthopedic examination was normal.

Magnetic resonance imaging of the cervical spine was performed. At C6-C7, there was an aggregation of material in the left ventral aspect of the vertebral canal and interverterbral foramen that was hypointense on T2W and STIR sequences with mild contrast enhancement on T1W sequence (Figure 3). This material resulted in mild left sixth spinal nerve root compression and minimal extradural spinal cord compression. Additionally, there was mild broad-based dorsal protrusion of the annulus fibrosis throughout the remainder of the cervical vertebral column, without spinal cord or nerve root compression.

Treatment options were discussed and the client elected fluoroscopically guided perineural injection of $5 \mathrm{mg}$ methylprednisolone $(1 \mathrm{mg} / \mathrm{kg})$ at the $\mathrm{C} 6-\mathrm{C} 7$ foramen. Anesthetic recovery was uneventful.

Only mild improvement in pain was noted during hospitalization. The patient was discharged with gabapentin $50 \mathrm{mg}$ (10 mg/kg) q8-12 h, tramadol $12.5 \mathrm{mg}(2.5 \mathrm{mg} / \mathrm{kg}) \mathrm{q} 8-12 \mathrm{~h}$, and prednisone $2.5 \mathrm{mg}(1 \mathrm{mg} / \mathrm{kg}) \mathrm{q} 12 \mathrm{~h}$ the following day. The owner reported that over the next couple of months the patient continued to improve at home and both the tramadol and prednisone were discontinued by the owner and family veterinarian. Six months later, the clients were contacted by phone and reported that they administered gabapentin only as needed after intense exercise.

\section{DISCUSSION}

Cervical transforaminal epidural steroid injections are performed for treatment of radicular pain in people (11-14). Humans typically have multiple affected sites; it is advantageous to administer medications epidurally, rather than perineurally, allowing for more complete diffusion (11). This carries greater risk of neurological complications. Because of the focal nature of disease in cases identified here and the decreased risk of complications, perineural injections were considered. Because perineural injection does not alter the structural nature of the disease, rest for 4 weeks was also recommended. This was felt to be necessary to avoid acute recurrence associated with recrudescence of inflammation or herniation of additional disk material at the same site.

Four of five dogs had immediate improvement in clinical signs, the last case only showed mild improvement (Case 5). Three out of five dogs had long-term pain relief (18 months to 4 years) after perineural injection without continued administration of oral analgesics or recurrence of clinical signs. The two dogs that received on-going medical therapy (Cases 3 and 5) were administered gabapentin at the owner's discretion.

One dog (Case 1) had significant complication of transient respiratory paralysis. Transient respiratory paralysis may have been caused by local anesthetic entering the epidural space and migrating cranially to result in depression of the respiratory centers at the craniocervical junction. Caudal migration of anesthetic and paralysis of the phrenic nerve could also explain this complication, although based on proximity this is considered less likely. Administration of a local anesthetic along with methylprednisolone was at the discretion of the clinician and based on results of Case 1 was not used in subsequent patients. Case 2 was affected at the same disk space (C3-C4), received steroid injection only, and experienced no complications. No other patient in this series experienced respiratory complications. Future studies

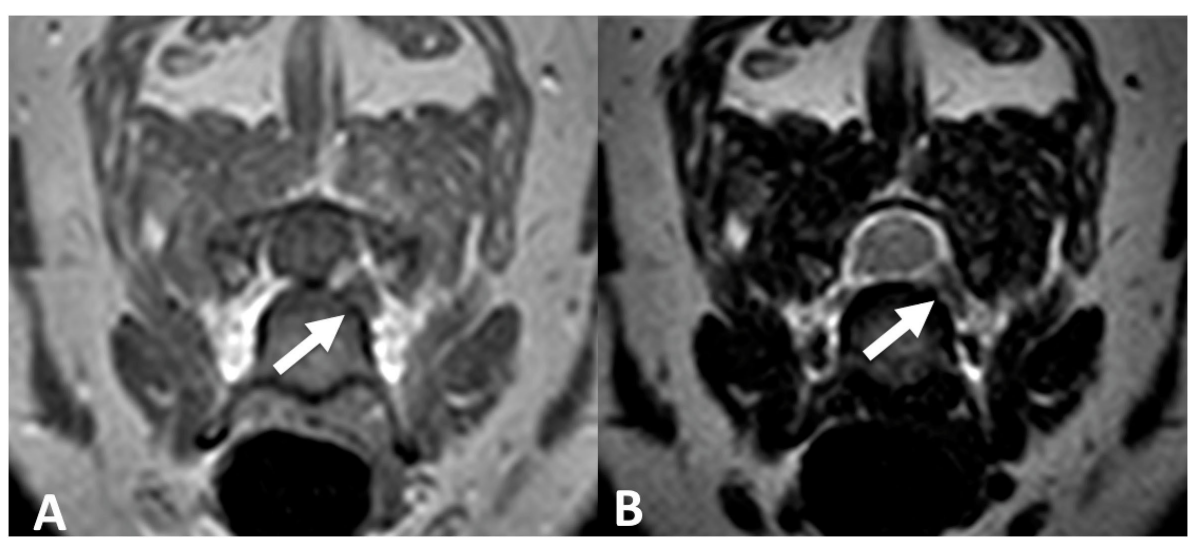

FIGURE 3 | Transverse T1-weighted (A) and T2-weighted (B) MR images of the cervical spine at the level of C6-C7 (Case 5). Hypointense extruded disk material is noted within the left intervertebral foramen on both sequences (arrows). 
are needed to evaluate the incidence of respiratory complications associated with injection technique, as well as to compare therapeutic benefit of steroid alone versus steroid in combination with local anesthetic.

In people, continued pain relief for 6-12 months following injection has been reported $(12,13)$. On-going relief of clinical signs may be attributable to the anti-inflammatory and antinociceptive properties of corticosteroids via decreased type C-fiber impulse transmission. C-fibers participate in chronic nerve pain, therefore blocking this transmission may result in prolonged relief of clinical signs (15). The anti-inflammatory properties of steroids may also contribute to membrane stabilization and reduction in nerve root swelling (16). Disk extrusions associated with Hansen type 1 degeneration in dogs are known to incite an inflammatory reaction that may play a role in the development of chemical meningitis or radiculitis (17). It is probable that steroids attenuate this reaction by inhibiting phospholipase A2 activity (18) and this may contribute to prolonged resolution of signs in some of our patients.

When single injections fail to produce sufficient long-term analgesia in people $(<6-12$ months), additional injections have been repeated with success $(19,20)$. Since no patient in this series re-presented for further evaluation and treatment, we cannot comment on use of repeat injections. However, failure to respond to perineural injection may be an indicator for surgical treatment.

Another theory explaining prolonged effects of epidural injection includes mechanical effects of the injection causing adhesion lysis, interruption of a reflex-sympathetic response, and membrane stabilization (21). Studies have also shown benefits of saline injection alone supporting the mechanical effects of the intervention and possible benefit from dilution of inflammatory mediators (22). None of our patients underwent repeat imaging or necropsy to assess mechanical effects or assess structural change. Lastly, inadvertent direct nerve injection could explain pain relief in some dogs; however, there was no sign of monoparesis or hyporeflexia supporting direct nerve injection.

No clients reported polyuria, polydipsia, alopecia, or weight gain to suggest significant systemic absorption of corticosteroid post-injection. However, the retrospective nature of this series precluded confirmation of suppression of the hypothyalamicpituitary-adrenal (HPA) axis in all cases. Systemic absorption of epidural steroid remains a deciding factor when choosing patient suitable for perineural injection. An increase in blood pressure and blood glucose, as well as a decrease in cortisol and ACTH, has been demonstrated up to a week post-injection in people (23). Jacobs et al. (24) demonstrated marked suppression of plasma cortisol levels for 3 weeks in people after single lumbar extradural injection of methylprednisolone acetate (24). Similar absorption

\section{REFERENCES}

1. Brisson BA. Intervertebral disc disease in dogs. Vet Clin North Am Small Anim Pract (2010) 40:829-58. doi:10.1016/j.cvsm.2010.06.001

2. Bagley RS, Tucker R, Harrington ML. Lateral and foraminal disk extrusion in dogs. Comp Cont Educ Pract Vet (1996) 18(7):795-804. during perineural injection has not been extensively studied and further studies are needed to determine whether dogs intolerant of oral steroid medication or those on oral non-steroidal antiinflammatory drugs may be better candidates for perineural administration of steroids.

Ultrasound has been used to identify vertebral anatomy with visualization of vascular tissue and individual nerve roots (25). Recent authors have described ultrasound-guided cervical intra-articular injections in canine cadavers, brachial plexus anesthesia in canine cadavers, and lumbar epidural in cadaver and live dogs (25-28). While ultrasound does not carry the risk of radiation exposure associated with fluoroscopy, it is more operator dependent and, at our institution, more expensive than fluoroscopy. Fluoroscopy was used to identify individual nerve roots for injection in the present study. CT offers the highest level of precision and accuracy but incurs a substantial cost compared to fluoroscopy and ultrasound (29). Pre-injection iodinated contrast could potentially improve technical precision in dogs with varied cervical morphology. However, in people, one prospective study found that the use of iodinated contrast did not affect the analgesic outcome (30). More rigorous assessment of risks of focal neuritis, seizures, and other neurological complications should be demonstrated prior to routine administration of contrast. Future studies are needed to compare the techniques in clinical patients.

\section{CONCLUDING REMARKS}

Perineural steroid administration may provide effective analgesia in some cases of cervical foraminal intervertebral disk herniation. The procedure is inexpensive and requires short duration of anesthesia. Three out of five patients showed significant improvement immediately after perineural injection, while the remaining two required only intermittent dosing with gabapentin. One dog had complications. Prospective studies comparing administered medications, technique, and followup imaging are needed. Large prospective studies are needed to better assess complication rate. Patients with significant intervertebral disk material in the canal are unlikely to benefit from the procedure described and surgery should remain the primary consideration.

\section{AUTHOR CONTRIBUTIONS}

All authors made substantial contributions to the work and assisted in drafting and revising the submission. Each author has given final approval of the version to be published and is accountable for all aspects of the work.

3. Smith BA, Hosgood G, Kerwin SC. Ventral slot decompression for cervical intervertebral disc disease in 112 dogs. Austr Vet Pract (1997) 27(2):58-64

4. Fry TR, Johnson AL, Hungerford L. Surgical treatment of cervical disc herniation in ambulatory dogs, ventral decompression vs fenestration, 111 cases (1980-1988). Prog Vet Neurol (1991) 2:165-73. 
5. Seim HB III, Prata RG. Ventral decompression for the treatment of cervical disk disease in the dog: a review of 54 cases. J Am Anim Hosp Assoc (1982) 18:233-40.

6. Bruecker KA, Seim HB, Withrow SJ. Clinical evaluation of three surgical methods for treatment of caudal cervical spondylomyelopathy of dogs. Vet Surg (1989) 18(3):197-203. doi:10.1111/j.1532-950X.1989.tb01070.x

7. De Risio L, Munana K, Murray M, Olby N, Sharp NJ, Cuddon P. Dorsal laminectomy for caudal cervical spondylomyelopathy: post-operative recovery and long term follow up in 20 dogs. Vet Surg (2002) 31(5):418-27. doi:10.1053/jvet.2002.34673

8. Shores A, Tepper LC. A modified ventral approach to the atlantoaxial junction in the dog. Vet Surg (2007) 36(8):765-70. doi:10.1111/j.1532-950X.2007.00334.x

9. Delamaide Gasper JA, Rylander H, Stenglein JL, Waller KR III. Osseousassociated cervical spondylomyelopathy in dogs: 27 cases (2000-2012). J Am Vet Med Assoc (2014) 244:1309-18. doi:10.2460/javma.244.11.1309

10. Rossmeisl JH, Lanz OL, Inzana KD, Bergman RL. A modified lateral approach to the canine cervical spine: procedural description and clinical application in 16 dogs with lateralized compressive myelopathy or radiculopathy. Vet Surg (2005) 34(5):436-44. doi:10.1111/j.1532-950X.2005.00066.x

11. Wilkinson IM, Cohen SP. Epidural steroid injections. Curr Pain Headache Rep (2012) 16(1):50-9. doi:10.1007/s11916-011-0236-9

12. Manchikanti L, Cash KA, Pampati V, Wargo BW, Malla Y. Cervical epidural injections in chronic discogenic neck pain without disc herniation or radiculitis: preliminary results of a randomized, double-blind, controlled trial. Pain Physician (2010) 13(4):E265-78.

13. Vallée JN, Feydy A, Carlier RY, Mutschler C, Mompoint D, Vallee CA. Chronic cervical radiculopathy: lateral-approach periradicular corticosteroid injection. Radiology (2001) 218(3):886-92. doi:10.1148/ radiology.218.3.r01mr17886

14. Strobel K, Pfirrman CWA, Schmid M, Holder J, Boos N, Zanetti M. Cervical nerve root blocks: indications and role of MR imaging. Radiology (2004) 233:87-92. doi:10.1148/radiol.2331030423

15. Johansson A, Hao J, Sjölund B. Local corticosteroid application blocks transmission in normal nociceptive C-fibres. Acta Anaesthesiol Scand (1990) 34(5):335-8. doi:10.1111/j.1399-6576.1990.tb03097.x

16. Green LN. Dexamethasone in the management of symptoms due to herniated lumbar disc. J Neurol Neurosurg Psychiatry (1975) 38(12):1211-7. doi:10.1136/ jnnp.38.12.1211

17. Windsor RC, Vernau KM, Sturges BK, Kass PH, Vernau W. Lumbar cerebrospinal fluid in dogs with type I intervertebral disc herniation. J Vet Intern Med (2008) 22(4):954-60. doi:10.1111/j.1939-1676.2008.0141.x

18. Saal JS, Franson RC, Dobrow R, Saal JA, White AH, Goldthwaite N. High levels of inflammatory phospholipase A2 activity in lumbar disc herniations. Spine (1990) 15(7):674-8. doi:10.1097/00007632-199007000-00011

19. Anderberg L, Annertz M, Persson L, Brandt L, Saveland H. Transforaminal steroid injections for the treatment of cervical radiculopathy: a prospective and randomised study. Eur Spine J (2007) 16(3):321-8. doi:10.1007/ s00586-006-0142-8
20. Bush K, Hillier S. Outcome of cervical radiculopathy treated with periradicular/epidural corticosteroid injections: a prospective study with independent clinical review. Eur Spine J (1996) 5(5):319-25. doi:10.1007/ BF00304347

21. Hayashi N, Weinstein JN, Meller ST, Lee HM, Spratt KF, Gebhart GF. The effect of epidural injection of betamethasone or bupivacaine in a rat model of lumbar radiculopathy. Spine (1998) 23(8):877-85. doi:10.1097/00007632-199804150-00008

22. Evans W. Intrasacral epidural injection in the treatment of sciatica. Lancet (1930) 216(5597):1225-9. doi:10.1016/S0140-6736(00)86498-3

23. Younes M, Neffati F, Touzi M, Hassen-Zrour S, Fendri Y, Bejia I, et al. Systemic effects of epidural and intra-articular glucocorticoid injections in diabetic and non-diabetic patients. Joint Bone Spine (2007) 74(5):472-6. doi:10.1016/j. jbspin.2006.10.009

24. Jacobs S, Pullan PT, Potter JM, Shenfield GM. Adrenal suppression following extradural steroids. Anaesthesia (1983) 38(10):953-6. doi:10.111 1/j.1365-2044.1983.tb12025.x

25. Bagshaw HS, Larenza MP, Seiler GS. A technique for ultrasound-guided paravertebral brachial plexus injections in dogs. Vet Radiol Ultrasound (2009) 50(6):649-54. doi:10.1111/j.1740-8261.2009.01599.x

26. Levy M, Gaschen L, Rademacher N, Bargulla $H$. Technique for ultrasound-guided intraarticular cervical articular process injection in the dog. Vet Radiol Ultrasound (2014) 55(4):435-40. doi:10.1111/vru.12143

27. Graff SM, Wilson DV, Guiot LP, Nelson NC. Comparison of three ultrasound guided approaches to the lumbar plexus in dogs: a cadaveric study. Vet Anaesth Analg (2014) 42(4):394-404.

28. Liotta A, Busoni V, Carrozzo MV, Sandersen C, Gabriel A, Bolen G. Feasibility of ultrasound-guided epidural access at the lumbo-sacral space in dogs. Vet Radiol Ultrasound (2015) 56(2):220-8. doi:10.1111/vru.12207

29. Chen B, Rispoli L, Stitik TP, Foye PM, Georgy JS. Optimal needle entry angle for cervical transforaminal epidural injections. Pain Physician (2014) 17(2):139-44.

30. Mallinson PI, Tapping CR, Bartlett R, Maliakai P. Factors that affect the efficacy of fluoroscopically guided selective spinal nerve root block in the treatment of radicular pain: a prospective cohort study. Can Assoc Radiol J (2013) 64(4):370-5. doi:10.1016/j.carj.2013.03.001

Conflict of Interest Statement: The authors declare that the research was conducted in the absence of any commercial or financial relationships that could be construed as a potential conflict of interest.

Copyright (c) 2016 Giambuzzi, Pancotto and Ruth. This is an open-access article distributed under the terms of the Creative Commons Attribution License (CC BY). The use, distribution or reproduction in other forums is permitted, provided the original author(s) or licensor are credited and that the original publication in this journal is cited, in accordance with accepted academic practice. No use, distribution or reproduction is permitted which does not comply with these terms. 